\section{A propósito de las Guías Latinoamericanas de la RIICER para el diagnóstico de las rickettsiosis transmitidas por garrapatas}

\section{Speaking of Latin American guidelines for the diagnosis of tick-transmitted rickettsiosis}

\section{Sr. Editor:}

Las rickettsiosis del grupo de las fiebres manchadas (GFM) son enfermedades infecciosas de carácter zoonótico, causadas por bacterias intracelulares estrictas del género Rickettsia, las cuales son transmitidas al hombre a través de la picadura de garrapatas ${ }^{1}$. En Latinoamérica, durante el siglo $\mathrm{XX}, R$. rickettsii era la única especie patógena reconocida del GFM; sin embargo, posterior al año 2000 , nuevas especies tales como $R$. parkeri, Rickettsia sp. cepa Atlantic rainforest y $R$. massiliae han sido implicadas como patógenos humanos. Actualmente éstas son, junto con $R$. rickettsii, las especies de mayor importancia. Las garrapatas de los géneros Amblyomma y Rhipicephalus son sus principales vectores en Latinoamérica ${ }^{2}$.

Tal como lo expone Oteo J A y cols., en la reciente publicación titulada "Guías Latinoamericanas de la RIICER para el diagnóstico de las rickettsiosis transmitidas por garrapatas "', los métodos de biología molecular, especialmente la técnica de reacción de polimerasa en cadena (RPC- en inglés polymerase chain reaction-PCR), han sido de gran utilidad en la descripción y caracterización de nuevas especies del género Rickettsia (patógenas o con potencial patógeno), tanto en muestras clínicas humanas como a partir de garrapatas ${ }^{1,4}$. En dicha Guía se sugiere la utilización de iniciadores específicos para la amplificación de secuencias parciales conservadas en el género Rickettsia, con el fin de identificar la especie involucrada, posterior secuenciación y comparación de secuencias por medio de la herramienta BLAST. Sin embargo, no existe claridad sobre la forma en que se deben utilizar estos protocolos de RPC, y específicamente si la amplificación de los fragmentos esperados debe realizarse por medio de reacciones sencillas o secuenciales (anidadas o semianidadas). Consideramos que este aspecto es fundamental, ya que interviene en la sensibilidad de este tipo de pruebas diagnósticas 5 .

De esta manera y con el fin de aportar al uso adecuado de estos protocolos para el diagnóstico molecular de las rickettsiosis transmitidas por garrapatas en Latinoamérica, queremos destacar los resultados publicados por Santibáñez y $\operatorname{cols}^{6}$. En este estudio se utilizaron muestras clínicas y garrapatas extraídas de pacientes con diagnóstico confirmado de rickettsiosis. El objetivo fue determinar la sensibilidad y utilidad de diferentes métodos de RPC. Se demostró que el método realizado por reacción sencilla, con el gen gltA (iniciadores CS-78 y CS-323), presentó las mayores tasas de resultados positivos, con porcentajes de sensibilidad de $33,3 \%$ en biopsias de piel y de $85,1 \%$ a partir garrapatas. Sin embargo, la sensibilidad aumentó considerablemente al utilizar los métodos de RPC con reacciones secuenciales. Se alcanzó una positividad entre 62,5 y $100 \%$ en muestras clínicas utilizando el gen отрB (anidada, iniciadores rompB OF/rompb OR seguido de rompB SFG IF/rompB SFG IR); de 92,6\% a partir de garrapatas utilizando el gen omp $A$ (semianidada, iniciadores $\operatorname{Rr} 190.70 \mathrm{p} / \operatorname{Rr} 190.701 \mathrm{n}$ seguido de $\operatorname{Rr} 190.70 \mathrm{p} /$ $\operatorname{Rr} 190.602 n) ; y$ una sensibilidad total de $100 \%$ al utilizar en combinación los tres métodos secuenciales (omp B, om$p A$ y glt $A$ anidada [iniciadores RpCS.877p/RpCS.1258n seguido de RpCS.896p/RpCS.1233n]).

Con lo anterior, consideramos que los futuros usuarios de las "Guías Latinoamericanas de la RIICER para el diagnóstico de las rickettsiosis transmitidas por garrapatas" tendrán mayor claridad respecto al uso adecuado de los iniciadores referenciados, dada la mayor sensibilidad de las reacciones secuenciales, especialmente con los genes oтp $B$ asociado a $g l t A$ a manera de tamizaje, y omp $A$ en la caracterización de especies de Rickettsia, a partir de muestras clínicas humanas y garrapatas.

\section{Referencias bibliográficas}

1.- Parola P, Paddock C D, Socolovschi C, Labruna M B, Mediannikov O, Kernif T, et al. Update on tick-borne rickettsioses around the world: a geographic approach. Clin Microbiol Rev 2013; 26: 657-702.

2.- Hidalgo M, Faccini-Martínez A A, Valbuena G. Rickettsiosis transmitidas por garrapatas en las Américas: avances clínicos y epidemiológicos, y retos en el diagnóstico. Biomédica 2013; 33 (Supl 1): 161-78.

3.- Oteo JA, Nava S, de Sousa R, Mattar S, Venzal J M, Abarca K, et al. Guías Latinoamericanas de la RIICER para el diagnóstico de las rickettsiosis transmitidas por garrapatas. Rev Chilena Infectol 2014; 31: 54-65.

4.- Eremeeva M E. Molecular epidemiology of rickettsial diseases in North America. Ticks Tick Borne Dis 2012; 3 : 332-7.

5.- Kim E J, Bauer C, Grevelding C G, Quack T. Improved $\mathrm{PCR} /$ nested PCR approaches with increased sensitivity and specificity for the detection of pathogens in hard ticks. Ticks Tick Borne Dis 2013; 4: 409-16.

6.- Santibáñez S, Portillo A, Santibáñez P, Palomar A M, Oteo J A. Usefulness of rickettsial PCR assays for the molecular diagnosis of human rickettsioses. Enferm Infecc Microbiol Clin 2013; 31: 283-8.

Álvaro A. Faccini-Martínez y Marylin Hidalgo
Departamento de Microbiología, Facultad de
Ciencias, Pontificia Universidad Javeriana,
Bogotá, Colombia.
Correspondencia a:
Álvaro A. Faccini-Martínez
afaccini@gmail.com

